\title{
Intervertebral disc vacuum phenomenon is associated with Modic changes in the adjacent endplate: implications for discogenic back pain
}

Junhui Liu

Department of Orthopaedics, Sir Run Run Shaw Hospital, School of Medicine, Zhejiang University

\section{Yufeng Xiang}

Department of Orthopaedic, Linhai Second People's Hospital

\section{Zhi Shan}

Department of Orthopaedics, Sir Run Run Shaw Hospital, School of Medicine, Zhejiang University

\section{Shunwu Fan}

Department of Orthopaedics, Sir Run Run Shaw Hospital, School of Medicine, Zhejiang University

Fengdong Zhao ( $\nabla$ zhaofengdong@zju.edu.cn)

Zhejiang University School of Medicine Sir Run Run Shaw Hospital https://orcid.org/0000-0002-29458707

Research article

Keywords: Vacuum phenomenon, Modic changes, intervertebral disc, degeneration, back pain

Posted Date: July 27th, 2020

DOl: https://doi.org/10.21203/rs.3.rs-38301/v2

License: (9) (1) This work is licensed under a Creative Commons Attribution 4.0 International License.

Read Full License 


\section{Abstract}

Background: Back pain often arises from degenerative changes in lumbar intervertebral discs and their adjacent endplates. A painful endplate is not easy to identify in patients, but it could be possibly revealed by inflammatory-like 'Modic' changes and by a 'vacuum phenomenon' within the disc. We hypothesize that Modic changes and a VP often co-exist in those lumbar levels most closely associated with back pain.

Methods: We scanned 1023 consecutive inpatients of the Department of Orthopaedics from 2015 August to 2018 August, all patients suffered from lumbar degenerative diseases. Whether the patients had back pain or not were evaluated, and the prevalence and location of vacuum phenomenon(VP) and Modic changes were compared at each spinal level.

Results: 5115 discs were studied from 1023 patients. The number of discs showed to have a VP was 430 using CT. Of the 430 discs with a CT-diagnosed VP, 116 were L4-5, and 171 were L5-S1. 522 of the 5115 discs exhibited Modic changes, with the prevalence of type I, type II and type III Modic changes being $1.6 \%, 8.2 \%$ and $0.4 \%$ respectively. Modic changes usually occurred adjacent to L4-5 discs or L5-S1 discs. The prevalence of back pain was higher in the VP group than no-VP group, VP were significantly associated with Modic changes Type II at L4/5 and at L5/S1.

Conclusion: VP are closely associated with back pain and Modic changes in the lower lumbar spine. Further investigations may be warranted when radiographs or CT identify a VP in a lumbar disc.

\section{Introduction}

Recent population studies have confirmed that back pain is closely associated with degenerative changes in lumbar intervertebral discs[1,2]. The vertebral body endplates, which consist of a hyaline cartilage layer weakly bonded to perforated cortical bone, have been specifically identified as a pain source[3]. Various endplate defects have been shown to be common in the lower lumbar spine[4]where they are closely associated with back pain[5].

Painful endplates are not easily identified in individual patients, but they could be possibly revealed by inflammatory-like 'Modic' changes(MCs), which are visible on MRI scans and which are known to be associated with back pain [6, 7]. De Roos[8] firstly described these vertebral endplate signal changes in 1987, and Modic $[9,10]$ described their clinical and histological features. They can be classified into three types: Type I lesions (Figure 1) involve low T1 and high T2 signals, and indicate an ongoing active degenerative process with vascularized fibrous tissue within the bone marrow; Type II lesions (Figure 2) involve high T1 and T2 signals, are more stable during a 3-year follow-up, and reflect fatty replacement of the bone marrow; Type III lesions (Figure 3) come later, involve low T1 and T2 signals, and are thought to associate with endplate sclerosis on plain film radiography[10]. The histological nature of type III changes remains undetermined. Many studies of Modic changes have focused on the lumbar vertebral endplate and its pathology[11-18]. 
Another possible indicator of a painful endplate is the presence of a 'vacuum phenomenon' (VP) within the adjacent disc. The VP, firstly reported over seventy years ago[19], comprises a localized radiolucency within the disc, and is presumed to represent a void filled with water, air or other gas. This interpretation is supported by the collapse in pressure in the nucleus pulposus of severely degenerated discs[20], especially following damage to an adjacent endplate[21, 22]. A VP has been reported on 1-3\% of spinal radiographs [23-25], with the incidence rising to $20 \%$ in elderly individuals[26]. The finding is accentuated on radiographs that are obtained during spinal extension, and obscured on those obtained during flexion.

It might be expected, therefore, that VP and Modic changes in the lumbar spine should be closely related to each other, and to the presence of a potentially-painful endplate lesion. A previous study on 200 patients has shown some correspondence between a VP in a lumbar disc (detected by CT) and Modic changes in an adjacent vertebral body (detected by MRI). The purpose of the present study was to confirm this finding in a larger patient population, and to extend it to include digital radiography (DR) which is often more widely available. We hypothesize that a VP revealed by DR or CT is a good indicator of Modic changes and, by implication, of underlying endplate pathology.

\section{Materials And Methods}

\section{Patients[}

We scanned 1023 consecutive inpatients( 452 women and 571 men; mean age, 60.2 years; age range, 37-87 years) of the Department of Orthopaedics who suffered from lumbar degenerative diseases (disc herniation, canal stenosis, scoliosis, spondylosis and degenerative spondylolisthesis etc) from 2015 August to 2018 August in author's hospital. Recruitment of patients for the study was limited to inpatients in the orthopedic wards. All patients underwent the DR, CT and MRI examination. Patients were excluded if they had an acute vertebral fracture, known or suspected spondylodiscitis, recent spinal surgery ( $<4$ months), or a history of malignant tumors. Whether the patients had back pain or not were evaluated. We also reviewed the DR, CT and MRI images of these 1023 patients. The presence, location and type of Modic changes and the presence and location of any VP were assessed. Ethical approval was obtained from Medical Ethics Committee of the author's hospital.

Digital Radiography and Computed Tomography. DR was performed on an X-ray unit (Bucky Diagnost CS, Philips), and CT scans were performed on a CT scanner (CT-SOMATOM Definition Flash, Siemens, Germany). A VP was defined on $\mathrm{CR}$ as linear horizontal radiolucent gas collection with sclerostic margin or appears in ovoid shape. A VP was defined on CT as spotted, linear or crescent gas collection

Magnetic Resonance Imaging: Lumbar MR images were obtained on a General Electric 1.5-T magnet using a T1-weighted sequence (repetition time [TR]/echo time [TE], $560 \mathrm{~ms} / 12 \mathrm{~ms}$; field of view, 320×256; receiver bandwidth, variable; $4.0-\mathrm{mm}$ slice with gap of $1.0 \mathrm{~mm}$; number of excitations, 3), and a T2weighted sequence (repetition time [TR]/echo time [TE], $3000 \mathrm{~ms} / 100 \mathrm{~ms}$; field of view, $320 \times 256$; receiver bandwidth, variable; $4.0-\mathrm{mm}$ slice with gap of $1.0 \mathrm{~mm}$; number of excitations. A VP was defined as a region of signal void on T1- or T2-weighted images. 
Imaging evaluation: The DR $\square \mathrm{CT}$ and MRI datasets was independently evaluated by an experienced radiologist and by an orthopedic surgeon, who were blinded to patient information. A consensus was reached in cases where there was initial disagreement.

Back Pain几Back pain was determined from interviews after stay in hospital. Patients were asked "Did you have complaints of the low back during the last month?" LBP was defined to be present if the answer was positive.

Statistical Analyses: All patient and image interpretation data were collected in an Excel (Microsoft, Redmond, Washington) database, and analyzed statistically using SPSS 18.0 software (PASW, Statistics, IBM, USA). The inter-observer reliability was analysed by Kappa test. Associations between VP and low back pain were assessed using Chi-Square Test, Associations between Modic changes and VP were assessed using Lamda's correlation test. Associations between the types of Modic changes and VP were further analyzed using Chi-Square Test, Logistic regression was used to examine the dependence of VP and Modic changes on gender and age. $P<0.05$ was considered statistically significant.

\section{Results}

The inter-observer Kappa values for determining the VP using DR, CT and MR are 0.782, 0.831 and 0.803. The inter-observer Kappa values for determining Modic changes type I, type II and type III are $0.774,0.824$ and 0.801 .

\section{Vacuum phenomenon:}

Of these 1023 patients, a VP at one or more disc levels was found in 279 patients (27.3\%) in their lumbar CT scan. Of the 5115 discs examined in these 1023 patients, 430 discs (8.4\%) showed a VP on CT (Figure 4). Digital radiography (DR) was much less sensitive: a VP was identified in 159(3.1\%) of 5115 discs, which were in $132(12.9 \%)$ of the 1023 patients. MRI scans showed a VP in $266(5.2 \%)$ of 5115 discs, which were in $181(17.7 \%)$ of the 1023 patients. The detailed summary of VP results in Table 1 showed that most discs with a VP were in the lower lumbar spine: CT results showed a VP in 171 of 1023 discs (16.7\%) at the L5/S1 level, compared with 116 of 1023 discs (11.3\%) at the L4/5 level. Curiously, CT identified many more VP in upper lumbar discs than did MRI, but this difference was less pronounced in the lower lumbar discs. There was no association between VP and gender or age at any spinal level.

\section{Modic changes:}

Of these 1023 patients, a MCs at one or more disc levels were found in 214 patients (20.9\%), and these changes affected $522(10.2 \%)$ of all 5115 discs. Type I, Type II and Type III changes were seen in 82 discs (1.6\%), 419 discs (8.2\%) and 20 discs (0.4\%) respectively. Modic changes mostly occurred at the L5-S1 level (225 of 1023 discs; $22.0 \%$ ) and at the L4/5 level (174 of 1023 discs; $17.0 \%$ ). There was no association between Modic changes and gender or age at any spinal level.

\section{Associations between VP and Low back pain:}


As shown in Table 2 comparing the prevalence of back pain of VP group and no-VP group, the prevalence of back pain was higher in the VP group than in the no-pain group $(p<0.05)$.

\section{Associations between VP and Modic changes:}

As shown in Table 3 comparing the prevalence of MCs of VP group (by CT) and no-VP group(by CT), the prevalence of MCs was higher in VP group than in no-VP group $(\mathrm{p}<0.05)$. Using Lamda's correlation test, we found the presence of a VP by CT was significantly correlated with the presence of Modic changes at the L5-S1 level $(p<0.05)$ and also at the L4-5 level $(p<0.05)$, but not at other levels $(P>0.05)$. Besides, at these two levels, associations between types of Modic changes and VP were further analyzed using a Chi-Square Test. We found that only Type II significantly correlated with the presence of VP $(p<0.05)$, but not at other types $(P>0.05)$.

\section{Discussion}

The 'vacuum' phenomenon represents a void in the nucleus pulposus filled with air and traces of other gases from surrounding tissues. A void can be created during disc degeneration by the loss of proteoglycans and water from the nucleus pulposus[27] or following endplate damage which allows the endplate to bulge into the vertebral body. In either case, the nucleus becomes 'stress-shielded' by the annulus, so that the pressure within it can fall almost to zero[20, 22]. Clefts from the nucleus can extend into fissures in the annulus, which can also become voids during movements such as hyperextension, and appear as a radiolucent area in the discal space in radiographs and CT scans. Alternatively, spinal flexion can cause the VP to decrease in size or even disappear. Hence, the presence of a VP identified by radiographs has long been equated with the presence of "degenerative" disc disease[23, 26]. In each instance, the location and appearance of the gas would appear to indicate the position and extent of cleft formation within the disc, thus providing information as to the nature of the underlying process. Other possible causes of VP include infection (which is also closely associated with Modic changes[28]), osteonecrosis, skeletal metastasis, Schmorls nodes, alkaptonuria, chymopapain chemonucleolysis, and surgical discectomy. Similar phenomena occur in synovial articulations: when vigorous movements distract the apposing articular surfaces, if there is little synovial fluid within the articular cavity, the increasing joint space creates a negative pressure, attracting gas from surrounding extracellular spaces and causing the familiar 'popping' sound.

On MRI scans, the classic appearance of a VP is a region of signal void on T1- or T2-weighted images. However, MRI is less sensitive in detecting VP compared with CT[29], as shown here in Table 1. Plain radiographs (DR) detect far fewer VP than $\mathrm{CT}$ because CT can remove the illusion caused by overlapping gas in intestines, alveola, or subcutaneous fat fold.

Although a VP is considered to mark end stage disc degeneration, the nutrition still may enter the disc space via the transudate from the diffusion pathway. It has been suggested that fluid flow into and within the disc may enhance the transport of larger molecules[30,31], and it is now understood that endplates do not generally become less permeable as age and degeneration progress[32]. 
Studies showed that VP could be related to low back pain, when standing up or rolling over, which may cause pressure changes in the intervertebral discs[33,34]. Similarly, studies demonstrated that low back pain might be aggravated by atmosphere depression in patients with lumbar disease associated with VP[35]. And our research found that the prevalence of back pain was higher in the VP group than in the no-VP group, which confirmed that VP should be related to low back pain

Many studies have investigated Modic changes, and it is evident that biomechanical and biochemical factors are both important. As the spine is a nonlinear viscoelastic structure and its vertebral body and endplates are 'weak links', Adams et al. [22]concluded that the loss of the nucleus pulposus, resulting from bulging into the adjacent vertebra, or desiccation and dehydration for severe degeneration, could cause stress concentrations on the endplates and subchondral bone trabeculae, resulting in the occurrence of microfractures. Increased communication between the vertebral bone and the disc nucleus could lead to inflammation, Modic changes, and infections[28]. Disc prolapse may also create Modic changes, because many herniations of disc material include hyaline cartilage which is presumably pulled off the underlying endplate, exposing cortical bone with many large perforations in it. Such events may explain the endplate 'erosions' which are common in the lower lumbar spine[4] where they are closely associated with Modic changes[36], and pain[5]Mechanical events readily explain why Modic changes are most common at the lowest two levels[36].

The prevalence of Modic changes varies from 18 to $62 \%$ in the patients with LBP, with different ratios for each type[7, 9, 37-40]. According to the results of previous studies, type I and type II are the most common patterns in the lumbar spine, although it is uncertain whether type II is more frequent than type I. Chung et al.[41] found 11 type I and 38 type II Modic changes in 590 lumbar vertebral endplates of 59 asymptomatic subjects. Weishaupt et al.[42], reported a distribution of $2 \%$ type I, $7 \%$ type II, and $2 \%$ type III. These studies showed type II is more frequent than type I, as in the present study.

In our study, we found that the presence of a VP was significantly correlated with the presence of Modic changes at the L5-S1 level and also at the L4-5 level, and we think that the endplate degeneration might be the origination of the VP. Due to the endplate calcification and activated cytokines, the transport pathway of the nutrition for the intervertebral disc was blocked, resulting in the metabolic unbalance and decrease of the synthesis of matrix structural proteins. It could promote the matrix decomposition, causing the quantity of matrix to decrease and the stress in intervertebral disc to change. As a result, the structure of intervertebral discs became unstable. While compression happened, the intravertebral cleft could occur and be gradually filled with gas, which may cause low back pain and aggravate the intervertebral discs.

Our study has some limitations. The relatively small sample size prevented us from seeking to correlate the severity of VP (reflected as the percentage of the volume of VP in disc) and the severity of Modic changes, as suggested by Wang et al.[43], and it probably explained why VP and Modic changes did not increase with age, as might be expected[36]. Besides, the study only focused on the influence of VP and 
Modic changes on low back pain. In this study, we did not rule out other condition for back pain, which may limit the accuracy of the study.

Nevertheless, we suggest that the results of the present study have clinical significance. They show that the presence of Modic changes can be anticipated by finding a VP on CT or plain radiographs. Recent research is showing how endplate lesions (as indicated by Modic changes) are strongly implicated in endplate injury, inflammation, infection and pain, so that the radiographic demonstration of a VP may be considered grounds for further imaging studies in patients with low back pain.

\section{Declarations}

\section{Ethics approval and consent to participate}

The study was reviewed and approved by the institutional review board and the ethics committee of our institution. Patients or their family members agreed to our study, and signed the informed consents.

\section{Consent for publication}

Not applicable

\section{Availability of data and materials}

The datasets used and analyzed during the current study are available from the corresponding author on reasonable request.

\section{Competing interests}

All authors state that we have no competing of interest.

\section{Fundings}

This study was partially supported by National Natural Science Foundation of China (project number 81871796 and 81802192).

\section{Authors' contributions}

All authors were involved in conception and design. Study design: JHL, YFX, SWF and FDZ. Study conduct: ZS, YFX and SWF. Data collection and analysis: JHL, YFX and ZS. Data interpretation: SWF, JHL and FDZ. Drafting manuscript: JHL, YFX, and FDZ. All authors take responsibility for the integrity of the data analysis.

\section{Acknowledgements}

NO 


\section{Authors' information}

1. Department of Orthopaedics, Sir Run Run Shaw Hospital, School of Medicine, Zhejiang University.

2. Department of Orthopaedic, Linhai Second People's Hospital, 198 Dubei Road, Duqiao, Linhai, Taizhou, 317016, PR China.

\section{Abbreviations}

Vacuum phenomenon (VP)

Modic changes (MCs)

Digital Radiography (DR)

Computed tomography (CT)

Magnetic Resonance Imaging (MRI)

\section{References}

1. Cheung KM, Karppinen J, Chan D, Ho DW, Song YQ, Sham P, Cheah KS, Leong JC, Luk KD (2009) Prevalence and pattern of lumbar magnetic resonance imaging changes in a population study of one thousand forty-three individuals. Spine 34:934-940. doi: 10.1097/BRS.0b013e3181a01b3f

2. de Schepper El, Damen J, van Meurs JB, Ginai AZ, Popham M, Hofman A, Koes BW, Bierma-Zeinstra SM (2010) The association between lumbar disc degeneration and low back pain: the influence of age, gender, and individual radiographic features. Spine 35:531-536. doi: 10.1097/BRS.0b013e3181aa5b33

3. Peng B, Chen J, Kuang Z, Li D, Pang X, Zhang X (2009) Diagnosis and surgical treatment of back pain originating from endplate. European spine journal : official publication of the European Spine Society, the European Spinal Deformity Society, and the European Section of the Cervical Spine Research Society 18:1035-1040. doi: 10.1007/s00586-009-0938-4

4. Wang Y, Videman T, Battié MC (2012) Lumbar vertebral endplate lesions: prevalence, classification, and association with age. Spine 37:1432-1439. doi: 10.1097/BRS.0b013e31824dd20a

5. Wang Y, Videman T, Battié MC (2012) ISSLS prize winner: Lumbar vertebral endplate lesions: associations with disc degeneration and back pain history. Spine 37:1490-1496. doi: 10.1097/BRS.0b013e3182608ac4

6. Kjaer P, Korsholm L, Bendix T, Sorensen JS, Leboeuf-Yde C (2006) Modic changes and their associations with clinical findings. European spine journal : official publication of the European Spine Society, the European Spinal Deformity Society, and the European Section of the Cervical Spine Research Society 15:1312-1319. doi: 10.1007/s00586-006-0185-x 
7. Albert HB, Manniche $C$ (2007) Modic changes following lumbar disc herniation. European spine journal : official publication of the European Spine Society, the European Spinal Deformity Society, and the European Section of the Cervical Spine Research Society 16:977-982. doi: 10.1007/s00586007-0336-8

8. de Roos A, Kressel H, Spritzer C, Dalinka M (1987) MR imaging of marrow changes adjacent to end plates in degenerative lumbar disk disease. AJR American journal of roentgenology 149:531-534. doi: 10.2214/ajr.149.3.531

9. Modic MT, Steinberg PM, Ross JS, Masaryk TJ, Carter JR (1988) Degenerative disk disease: assessment of changes in vertebral body marrow with MR imaging. Radiology 166:193-199. doi: 10.1148/radiology.166.1.3336678

10. Modic MT, Masaryk TJ, Ross JS, Carter JR (1988) Imaging of degenerative disk disease. Radiology 168:177-186. doi: 10.1148/radiology.168.1.3289089

11. Vital JM, Gille O, Pointillart V, Pedram M, Bacon P, Razanabola F, Schaelderle C, Azzouz S (2003) Course of Modic 1 six months after lumbar posterior osteosynthesis. Spine 28:715-720; discussion 721. doi: 10.1097/01.brs.0000051924.39568.31

12. Schmid G, Witteler A, Willburger R, Kuhnen C, Jergas M, Koester O (2004) Lumbar disk herniation: correlation of histologic findings with marrow signal intensity changes in vertebral endplates at MR imaging. Radiology 231:352-358. doi: 10.1148/radiol.2312021708

13. Kuisma M, Karppinen J, Niinimäki J, Ojala R, Haapea M, Heliövaara M, Korpelainen R, Taimela S, Natri A, Tervonen $O$ (2007) Modic changes in endplates of lumbar vertebral bodies: prevalence and association with low back and sciatic pain among middle-aged male workers. Spine 32:1116-1122. doi: 10.1097/01.brs.0000261561.12944.ff

14. Karchevsky M, Schweitzer ME, Carrino JA, Zoga A, Montgomery D, Parker L (2005) Reactive endplate marrow changes: a systematic morphologic and epidemiologic evaluation. Skeletal radiology 34:125-129. doi: 10.1007/s00256-004-0886-3

15. Jones A, Clarke A, Freeman BJ, Lam KS, Grevitt MP (2005) The Modic classification: inter- and intraobserver error in clinical practice. Spine 30:1867-1869. doi:

10.1097/01.brs.0000173898.47585.7d

16. Kuisma M, Karppinen J, Haapea M, Lammentausta E, Niinimäki J, Tervonen $O$ (2009) Modic changes in vertebral endplates: a comparison of MR imaging and multislice CT. Skeletal radiology 38:141147. doi: $10.1007 / \mathrm{s} 00256-008-0590-9$

17. Beaudreuil J, Orcel P (2009) Modic 1 discopathy. Joint, bone, spine : revue du rhumatisme 76:4-6. doi: 10.1016/j.jbspin.2008.07.010

18. Albert HB, Kjaer P, Jensen TS, Sorensen JS, Bendix T, Manniche C (2008) Modic changes, possible causes and relation to low back pain. Medical hypotheses 70:361-368. doi:

10.1016/j.mehy.2007.05.014

19. Resnick D, Niwayama G, Guerra J, Jr., Vint V, Usselman J (1981) Spinal vacuum phenomena: anatomical study and review. Radiology 139:341-348. doi: 10.1148/radiology.139.2.7220878 
20. Sato K, Kikuchi S, Yonezawa T (1999) In vivo intradiscal pressure measurement in healthy individuals and in patients with ongoing back problems. Spine 24:2468-2474. doi:

10.1097/00007632-199912010-00008

21. Luo J, Skrzypiec DM, Pollintine P, Adams MA, Annesley-Williams DJ, Dolan P (2007) Mechanical efficacy of vertebroplasty: influence of cement type, BMD, fracture severity, and disc degeneration. Bone 40:1110-1119. doi: 10.1016/j.bone.2006.11.021

22. Dolan P, Luo J, Pollintine P, Landham PR, Stefanakis M, Adams MA (2013) Intervertebral disc decompression following endplate damage: implications for disc degeneration depend on spinal level and age. Spine 38:1473-1481. doi: 10.1097/BRS.0b013e318290f3cc

23. Raines JR (1953) Intervertebral disc fissures (vacuum intervertebral disc). The American journal of roentgenology, radium therapy, and nuclear medicine 70:964-966

24. Marr JT (1953) Gas in intervertebral discs. The American journal of roentgenology, radium therapy, and nuclear medicine 70:804-809

25. Ford LT, Goodman FG (1966) X-ray studies of the lumbosacral spine. Southern medical journal 59:1123-1128. doi: 10.1097/00007611-196610000-00001

26. Gershon-Cohen J, Schraer H, Sklaroff DM, Blumberg N (1954) Dissolution of the intervertebral disk in the aged normal; the phantom nucleus pulposus. Radiology 62:383-387. doi: 10.1148/62.3.383

27. Antoniou J, Steffen T, Nelson F, Winterbottom N, Hollander AP, Poole RA, Aebi M, Alini M (1996) The human lumbar intervertebral disc: evidence for changes in the biosynthesis and denaturation of the extracellular matrix with growth, maturation, ageing, and degeneration. The Journal of clinical investigation 98:996-1003. doi: 10.1172/jci118884

28. Albert HB, Lambert P, Rollason J, Sorensen JS, Worthington T, Pedersen MB, Nørgaard HS, Vernallis A, Busch F, Manniche C, Elliott T (2013) Does nuclear tissue infected with bacteria following disc herniations lead to Modic changes in the adjacent vertebrae? European spine journal : official publication of the European Spine Society, the European Spinal Deformity Society, and the European Section of the Cervical Spine Research Society 22:690-696. doi: 10.1007/s00586-013-2674-z

29. Coulier B (2004) The spectrum of vacuum phenomenon and gas in spine. JBR-BTR : organe de la Societe royale belge de radiologie $(\mathrm{SRBR})=$ orgaan van de Koninklijke Belgische Vereniging voor Radiologie (KBVR) 87:9-16

30. Ferguson SJ, Ito K, Nolte LP (2004) Fluid flow and convective transport of solutes within the intervertebral disc. Journal of biomechanics 37:213-221. doi: 10.1016/s0021-9290(03)00250-1

31. Yao H, Gu WY (2006) Physical signals and solute transport in human intervertebral disc during compressive stress relaxation: 3D finite element analysis. Biorheology 43:323-335

32. Rodriguez AG, Slichter CK, Acosta FL, Rodriguez-Soto AE, Burghardt AJ, Majumdar S, Lotz JC (2011) Human disc nucleus properties and vertebral endplate permeability. Spine 36:512-520. doi: 10.1097/BRS.0b013e3181f72b94

33. Morishita K, Kasai Y, Uchida A (2008) Clinical symptoms of patients with intervertebral vacuum phenomenon. The neurologist 14:37-39. doi: 10.1097/NRL.0b013e3180dc9992 
34. Madigan L, Vaccaro AR, Spector LR, Milam RA (2009) Management of symptomatic lumbar degenerative disk disease. The Journal of the American Academy of Orthopaedic Surgeons 17:102111. doi: 10.5435/00124635-200902000-00006

35. Kasai Y, Takegami K, Uchida A (2002) Change of barometric pressure influences low back pain in patients with vacuum phenomenon within lumbar intervertebral disc. Journal of spinal disorders \& techniques 15:290-293. doi: 10.1097/00024720-200208000-00005

36. Wang Y, Videman T, Battié MC (2012) Modic changes: prevalence, distribution patterns, and association with age in white men. The spine journal : official journal of the North American Spine Society 12:411-416. doi: 10.1016/j.spinee.2012.03.026

37. Besalti O, Pekcan Z, Sirin YS, Erbas G (2006) Magnetic resonance imaging findings in dogs with thoracolumbar intervertebral disk disease: 69 cases (1997-2005). Journal of the American Veterinary Medical Association 228:902-908. doi: 10.2460/javma.228.6.902

38. Kleinstück F, Dvorak J, Mannion AF (2006) Are "structural abnormalities" on magnetic resonance imaging a contraindication to the successful conservative treatment of chronic nonspecific low back pain? Spine 31:2250-2257. doi: 10.1097/01.brs.0000232802.95773.89

39. Mitra D, Cassar-Pullicino VN, McCall IW (2004) Longitudinal study of vertebral type-1 end-plate changes on MR of the lumbar spine. European radiology 14:1574-1581. doi: 10.1007/s00330-0042314-4

40. Toyone T, Takahashi K, Kitahara H, Yamagata M, Murakami M, Moriya H (1994) Vertebral bonemarrow changes in degenerative lumbar disc disease. An MRI study of 74 patients with low back pain. The Journal of bone and joint surgery British volume 76:757-764

41. Chung CB, Vande Berg BC, Tavernier T, Cotten A, Laredo JD, Vallee C, Malghem J (2004) End plate marrow changes in the asymptomatic lumbosacral spine: frequency, distribution and correlation with age and degenerative changes. Skeletal radiology 33:399-404. doi: 10.1007/s00256-004-0780-z

42. Weishaupt D, Zanetti M, Hodler J, Boos N (1998) MR imaging of the lumbar spine: prevalence of intervertebral disk extrusion and sequestration, nerve root compression, end plate abnormalities, and osteoarthritis of the facet joints in asymptomatic volunteers. Radiology 209:661-666. doi: 10.1148/radiology.209.3.9844656

43. Wang Y, Videman T, Niemeläinen R, Battié MC (2011) Quantitative measures of modic changes in lumbar spine magnetic resonance imaging: intra- and inter-rater reliability. Spine 36:1236-1243. doi: 10.1097/BRS.0b013e3181ecf283

\section{Tables}

Table 1. The distribution of discal segments with VP on DR, CT and MRI

\begin{tabular}{llllll}
\hline & L1-2 & L2-3 & L3-4 & L4-5 & L5-S1 \\
\hline DR & 6 & 10 & 26 & 53 & 64 \\
CT & 34 & 53 & 56 & 116 & 171 \\
MRI & 20 & 27 & 30 & 73 & 116 \\
\hline
\end{tabular}

Page 11/14 
Table 2 The association between VP and Low back pain

\begin{tabular}{crcc}
\hline \multicolumn{2}{c}{ Back pain } & No-pain \\
\hline VP & 183 & 96 \\
No-VP & 94 & 650 \\
\hline
\end{tabular}

Table 3 The association between VP and MC

\begin{tabular}{|c|c|c|}
\hline$M C$ & & $N o-M C$ \\
\hline $\mathrm{VP}$ & 183 & 96 \\
\hline No-VP & 31 & 713 \\
\hline
\end{tabular}

\section{Figures}
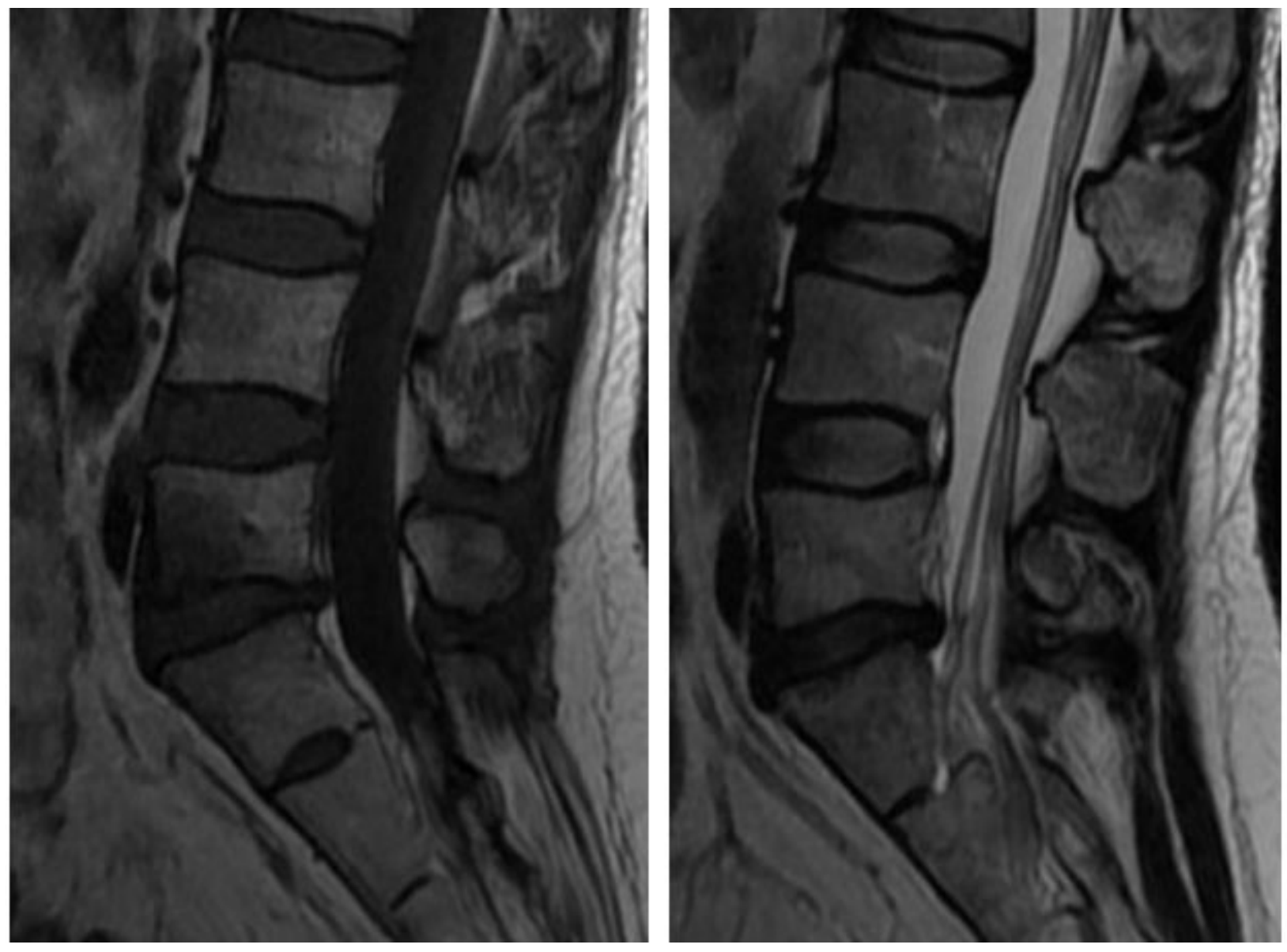

Figure 1 
Modic changes type I: Low signal intensity on the endplate of L5 on T1 image, but high signal on T2 image.
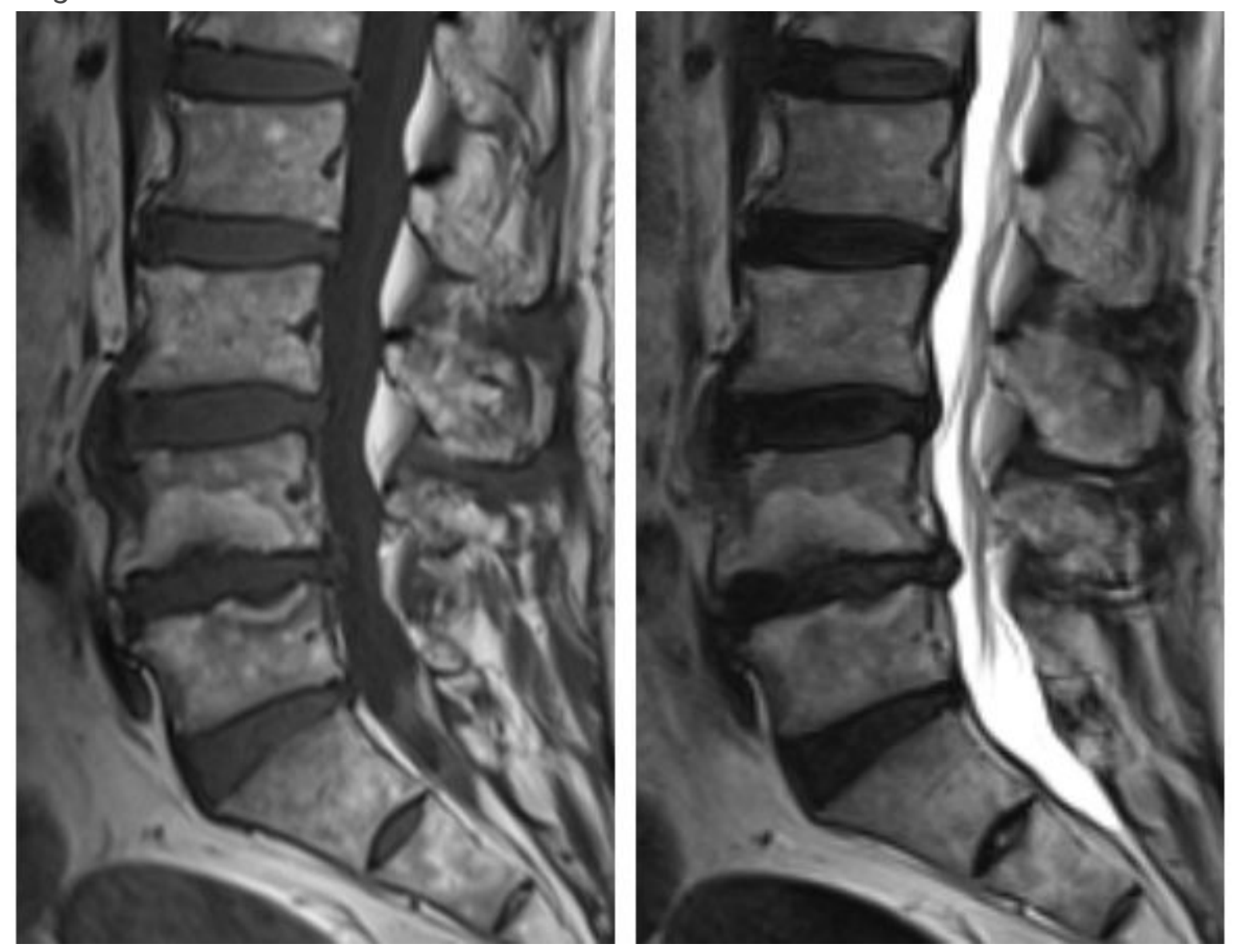

\section{Figure 2}

Modic changes type II: High signal intensity on both T1 and T2 image $\mathbb{L} 4-5 \rrbracket$. 

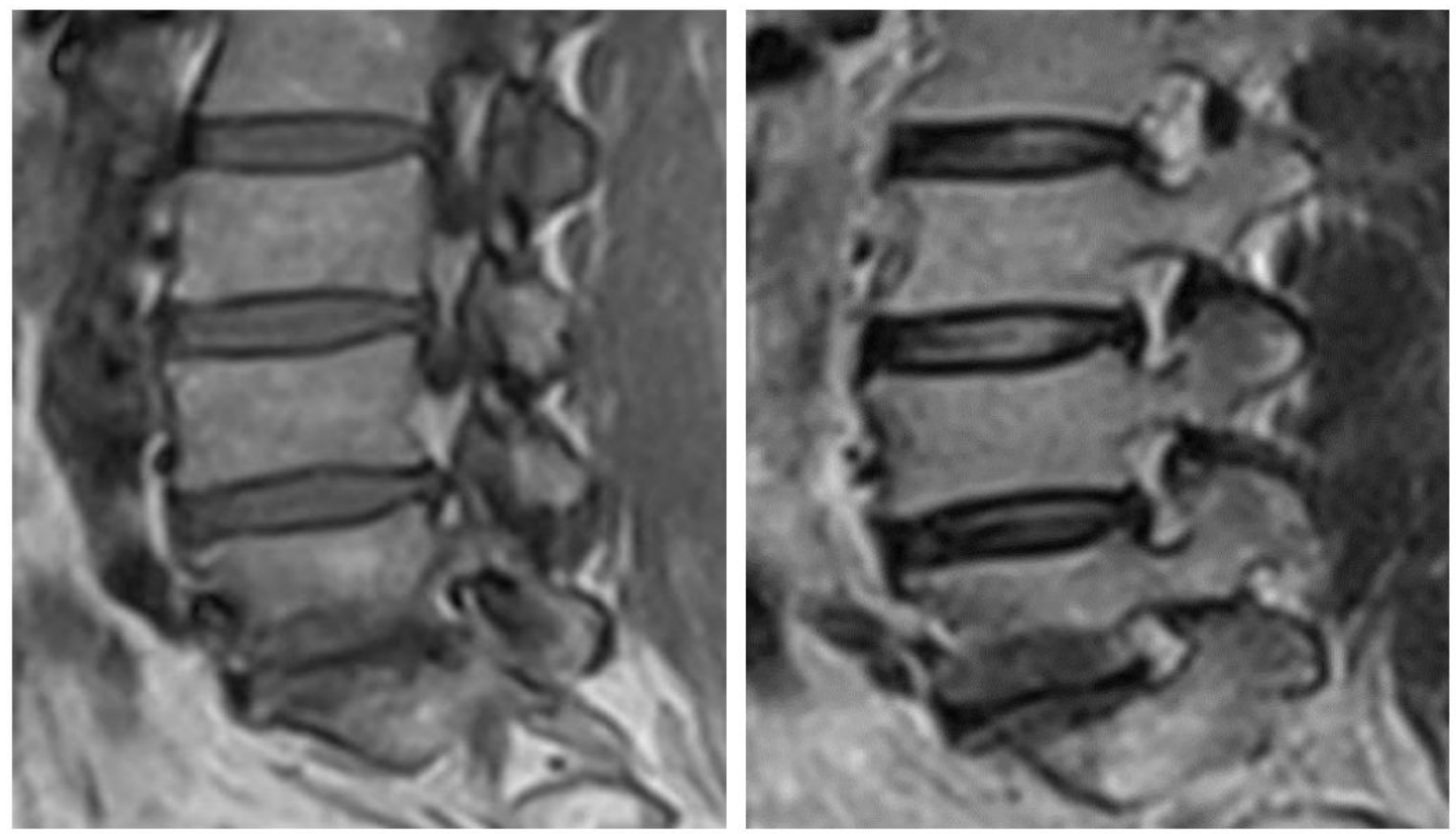

\section{Figure 3}

Modic changes type III: Low signal intensity on both T1 and T2 image $\mathbb{L}$ L5-S1区.

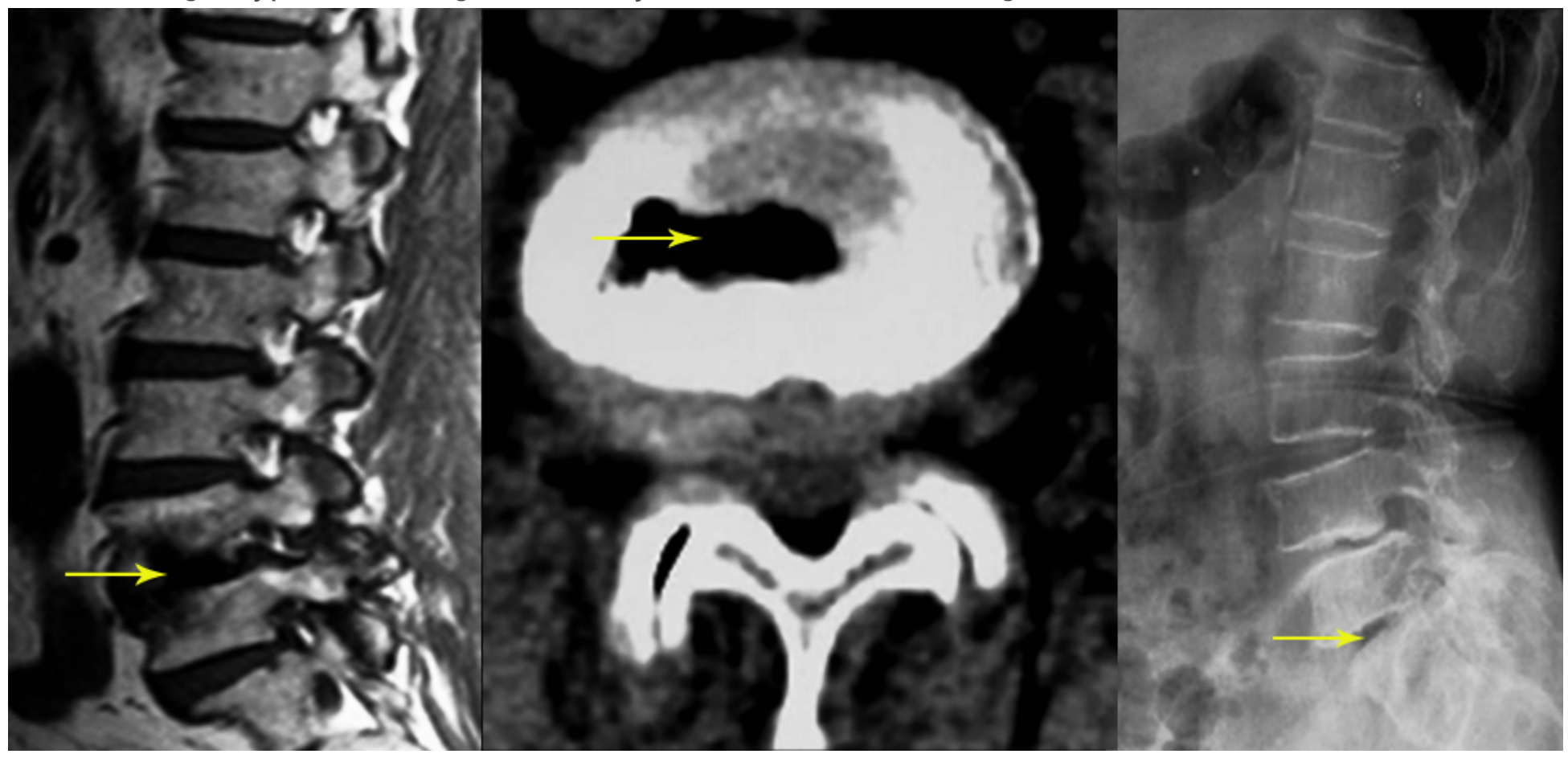

Figure 4

Vacuum phenomenon on MRI, CT and DR. 